\section{Endoscopic and radiologic appearance of giant esophageal hemangioma}
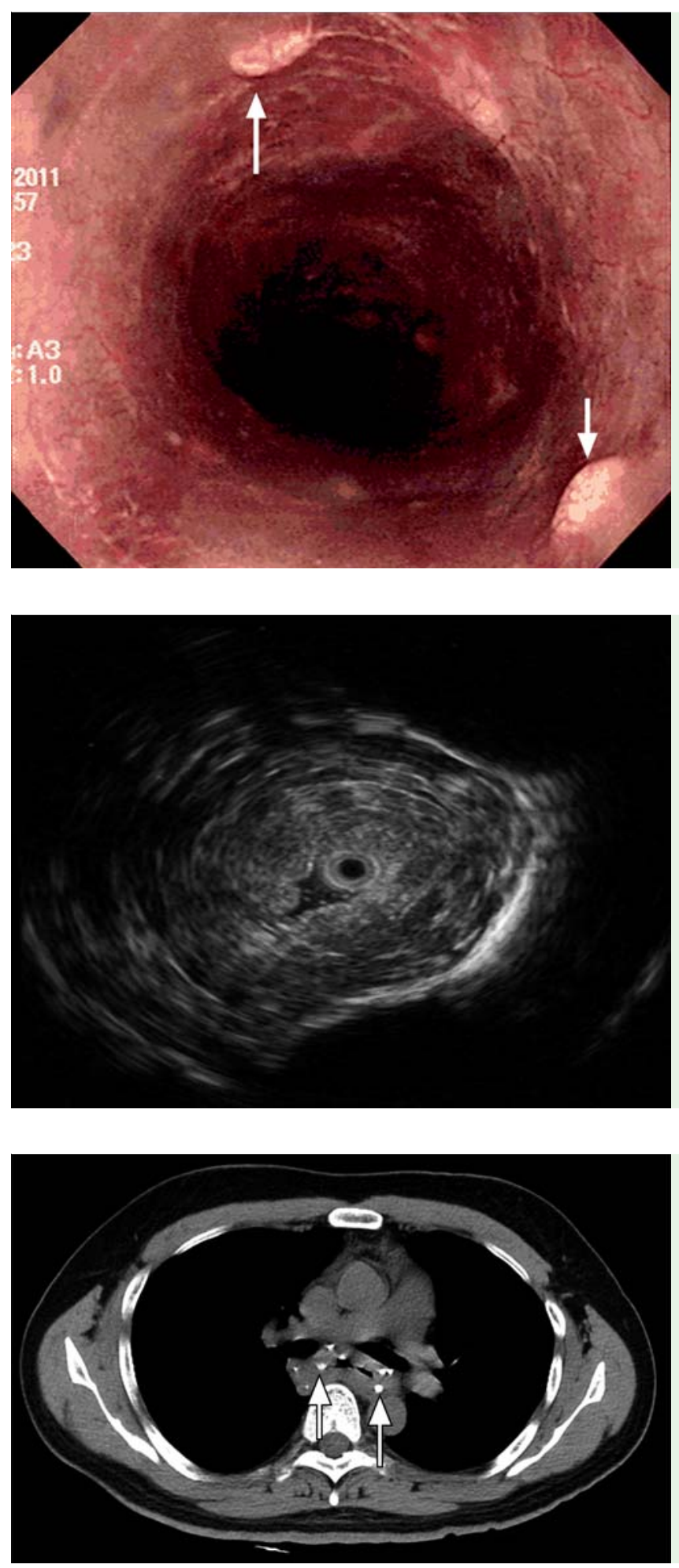

Fig. 1 Endoscopic appearance of the circumferentially affected esophageal area: it was easily distensible with dark purple mucosa and several calcified spots protruded into the lumen.

Fig. 2 Endoscopic ultrasonography (EUS) showed a giant hypoechoic tumor involving all layers of the affected esophagus.

Fig. 3 The pre-contrast phase of a computed tomography (CT) scan showed multiple calcifications (arrows) within the tumor.
A 38-year-old man presented to our hospital with long-term palpitations and acid regurgitation. A previous endoscopy at another clinic had led to the impression that esophageal varices were present. We repeated the endoscopy, which revealed circumferential dark purple mucosa extending from the upper to the middle third of the esophagus; it was easily distensible and the mucosal surface was smooth, except for calcified spots protruding into the lumen ( $\mathbf{F i g} . \mathbf{1}$ ). Endoscopic ultrasound showed a large hypoechoic tumor within the wall of the affected esophagus that involved all layers ( $\mathrm{Fig} .2$ ).

Contrast-enhanced dynamic computed tomography (CT) was done. In the precontrast phase, multiple calcifications ( $\bullet$ Fig.3) were noted. These were within a circumferential soft tumor, $22 \mathrm{~cm}$ in length, with delayed enhancement within the wall of the esophagus, that was revealed by the contrast-enhanced computed tomography ( $\bullet$ Fig. 4 and $\bullet$ Fig. 5 ).

We diagnosed a benign esophageal hemangioma. After consultation with the surgeon, a decision was made for followup only, as the patient had no symptoms or signs. The patient was still stable after 2 years of follow-up.

Esophageal hemangiomas are extremely rare, with a reported frequency of $3.3 \%$ of benign esophageal tumors [1]. Esophageal hemangioma patients are usually asymptomatic, but obstruction and life-threatening hemorrhages have been reported in rare symptomatic cases. The hemangioma usually presents with a submucosal tumor in endoscopic examination. Typically, the overlying bluish mucosa can be easily seen. The hemangioma is soft and the esophagus is distensible. The lesion blanches when gently pressed with the forceps. Clinicians should be aware of the risk of bleeding; this is why we did not take a biopsy.

To our knowledge, this is the largest reported hemangioma. We also endoscopically identified phleboliths which are seldom reported. The standard treatment is surgical resection by esophagectomy or enucleation. Many researchers report successful endoscopic resection, such as polypectomy or endoscopic mucosal resection [2]. However success has been limited to small $(<2.5 \mathrm{~cm}$ diameter) or pedunculated tumors and in this case the hemangioma was too large for endoscopic treatment. 


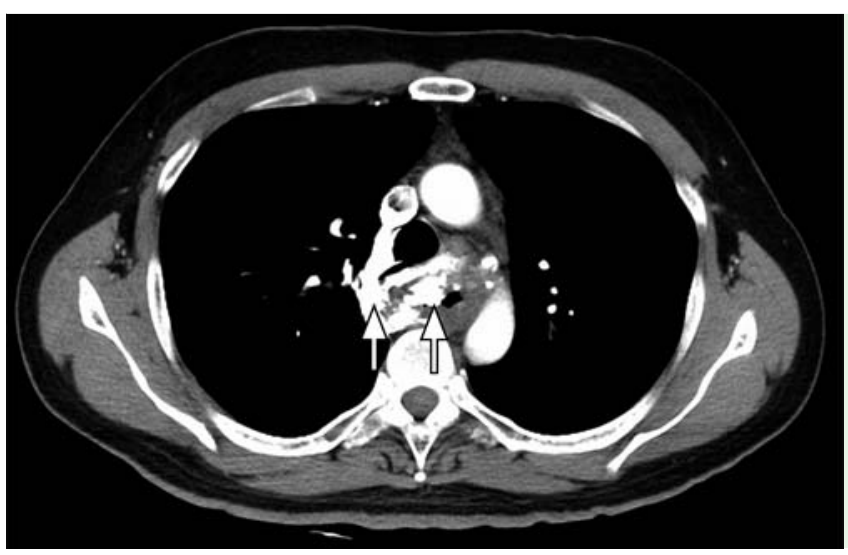

Fig. 4 Contrastenhanced computed tomography (CT) revealed a circumferential soft tumor with delayed enhancement within the esophagus wall (arrows).

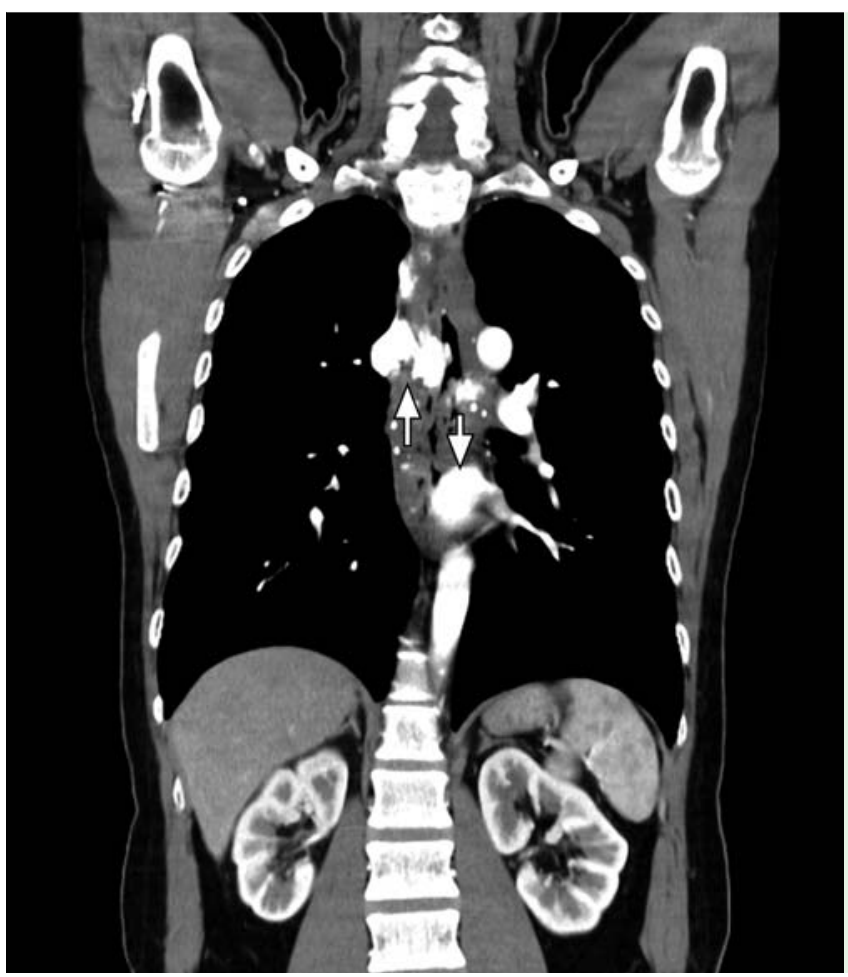

Fig. 5 Reconstruction of the computed tomography (CT) scan also showed a giant tumor, with delayed enhancement of the tumor (arrows).
Endoscopy_UCTN_Code_CCL_1AB_2AC_3AB

\section{Competing interests: None}

\section{Yang-Yuan Chen', Chih-Ming Lin', Yung-Fang Chen ${ }^{2}$}

${ }^{1}$ Division of Gastroenterology, China Medical University Hospital, China Medical University, Taichung, Taiwan

2 Division of Radiology, China Medical University Hospital, China Medical University, Taichung, Taiwan

\section{References}

1 Plachta A. Benign tumors of the esophagus. Review of literature and report of 99 cases. Am J Gastroenterol 1962; 38: 639-652

2 Yoshikane H, Suzuki T, Yoshioka N et al. Hemangioma of the esophagus: endosonographic imaging and endoscopic resection. Endoscopy 1995; 27: 267-269

\section{Bibliography}

DOI http://dx.doi.org/

10.1055/s-0034-1377219

Endoscopy 2015; 47: E45-E46

(c) Georg Thieme Verlag KG

Stuttgart · New York

ISSN 0013-726X

\section{Corresponding author}

\section{Yang-Yuan Chen, MD}

China Medical University Hospital

China Medical University

3 Lane 138 Tai-An 2nd Street Changhua, 500

Taiwan

Fax: +886-4-7228289

ychen02@gmail.com 